lateral and retrograde flow of the dye into other lymph vessels. These features are never seen in normal lymphatics.

We wish to thank Professor Sir James Paterson Ross and the other members of the Surgical Professorial Unit at St. Bartholomew's Hospital for their help and encouragement in developing this method.

REFERENCES

Kinmonth. J. B. (1951). Communication to Medical Research Society, London (February, 1951).

(1952). Clin. Sci., 11, 13

(1954). Ann. roy. Coll. Surg. Engl., 15, 300.

- and Taylor, G. W. (1954). Ann. Surg., 139, 129.

Moniz, E., Pinto, A.., and Lima, A. (1932). Röntgenpraxis, 4, 90.

dos Santos, J. C. (1938). J. int. Chir., 3, 625.

Santos, R., Lamas, A. C., and Caldas, J. P. (1931). Artériographie et de laorte abdominale. Masson, Paris.

\section{THE DELLWOOD FIRE}

\author{
BY
}

MARIAN E. COX, L.R.C.P.\&S.I., D.C.H.

Registrar, Paediatric Department, Royal Berkshire Hospital, Reading

BARBARA F. HESLOP, M.D.

Research Fellow, Department of Morbid Anatomy, Hospital for Sick Children, Great Ormond Street, London

\section{J. J. KEMPTON, M.D., M.R.C.P.}

Paediatrician, Reading Area Hospitals

AND

\section{R. A. RATCLIFF, M.D.}

Assistant Paediatrician, Reading Area Hospitals

In the early morning of Easter Sunday, April 18, 1954, a fire occurred in the nursery of Dellwood Maternity Home, Reading, which resulted in the death of 13 newborn babies. Dellwood is a general-practitioner obstetric unit of 17 lying-in beds dealing with normal cases. The hospital staff serve in a consultant capacity. The building is about fifty years old and there have been a few structural alterations during the twenty-four years of its use as a maternity home. The nursery measures 20 by $12 \mathrm{ft}$. (6.1 by 3.6 metres), with two doors and two windows: the floor boards are of deal covered by linoleum.

The fire was caused by the flue of a hot-water boiler which in September, 1953, had been moved so that it ran beneath the floor of the nursery. It has been established by subsequent inquiry that the installation of the flue complied with the local building regulations, though the experts who assisted the Regional Board in their inquiry agreed that the regulations need overhauling. It seems likely that the fire began slowly, with much smouldering of wood over a large area of floor. This, the destructive distillation of soft wood and also of some inoleum, filled the room with thick smoke, until finally part of the floor caught alight and the flames spread to one of the cots. It is thought that the room may have been filled with smoke for between 20 and 30 minutes.

There were 15 babies in the nursery, the doors of which were closed, while the windows were kept slightly open. A gas fire was burning. A nursing staff of two were on duty and the nursery was visited at intervals during the night, the last visit before the fire being about 3.15 a.m. The fire was discovered by one of the sisters*

* Sister E. M. Holland was later decorated with the George Medal by Her Majesty the Queen. at 4 a.m., and she immediately began to remove the babies from the room while help was being called. While removing the first babies she received considerable burns of face and arms and was in great distress from inhalation of smoke; she continued to bring them out one by one, and finally collapsed when the last one had been carried out. She was subsequently admitted to hospital.

One of us (R. A. R.) first saw the babies at 4.30 a.m. One whose cot had caught fire was dead following extensive burns involving the whole body, with some charring. Three others were transferred to the Battle Hospital at once and placed in oxygen boxes. One of these had some superficial burns of the face. All three were limp and pallid and in great respiratory distress. There was much clear viscid discharge from nose and eyes and complete nasal obstruction. The remaining 11 babies were in good general condition, but all were coughing a little and had some discharge from the nose and eyes. Their colour was generally good apart from slight occasional cyanosis produced by coughing attacks and interference with breathing by nasal obstruction. During the day there was some deterioration.' Respiratory rates were rising, and in all cases cough had increased: a little clear yellow fluid was occasionally coughed up or aspirated. Scattered rales, in every case, became audible in the afternoon and evening. Oxygen boxes had by this time been obtained for all the cases.

That evening it was decided to clear a hospital ward and make special arrangements for nursing staff, and early on Monday morning all the surviving babies were transferred in oxygen boxes to the Royal Berkshire Hospital. An alarming increase in respiratory obstruction developed in all the cases, and on Monday evening it seemed unlikely that any of the babies would survive. The appearances were similar to those with which we are familiar in asphyxia due to hyaline membrane, with, in addition, signs of upper respiratory tract irritation ; but these were strong infants several days old, and were making very forcible efforts to breathe, whereas in hyaline membrane asphyxia we are dealing usually with a shocked or feeble baby. Thus the characteristic contrast between struggling respiratory effort and poor breath sounds on auscultation was very striking.

Two of the babies began to improve after the third day and finally appear to have made a good recovery. There is no reason to suppose that these two suffered less exposure to the smoke than any of the others.

\section{Treatment}

All the babies were given oxygen, the first three being placed in oxygen boxes on admission to hospital, and the remainder (who at first stayed at Dellwood) being similarly treated later on the first day when chest signs were appearing and extra boxes had been obtained. Before this, some oxygen was given by tube and funnel or catheter when coughing attacks led to cyanosis. Mucous secretions were aspirated at intervals as needed, and 5\% sulphacetamide was applied to the nose and eyes. Penicillin was given in all cases, starting on the morning of the first day with 100,000 units eight-hourly by injection. The dose was later reduced and given orally to the babies who survived. Humidification was maintained by electric steam-kettles.

At midday on Monday, the day after the fire, streptomycin (100 mg. eight-hourly) and cortisone $(50 \mathrm{mg}$., then $25 \mathrm{mg}$. eight-hourly) were added to the treatment.

The babies were nursed with the foot of the cot raised and were kept for most of the time in a high concentration 
of oxygen, with a flow of four to five litres a minute. The position was altered from side to side at two-hourly intervals and aspiration of the nose and pharynx was carried out by catheter and electric sucker very frequently. Temperature and respiratory rates were recorded at hourly, and later at two-hourly, intervals. Feeds, at first of glucose-saline and later of milk mixture, were given by oesophageal tube during the first 48 hours. Aspiration of the trachea was attempted in three cases without apparent benefit, and hardly any mucus was obtained by this method. Gastric oxygen was given to several babies in extremis, and in one of these it was noted that the colour improved and was maintained for about half an hour after all respiratory movement had ceased.

In those babies who survived the first $\mathbf{4 8}$ hours percussion drainage was attempted in addition to postural drainage and frequent changing of position. This seemed to produce some good results : mucus was coughed up and aeration seemed to have improved. In one baby (one of those who recovered) a large bronchial cast was aspirated from the nose on the sixth day, after one of these periods of percussion drainage.

\section{Outline Course of Individual Cases}

Case 1.-Male aged 6 hours. Died during fire. Extensive burns and charring.

Case 2.-Female aged 6 days. Superficial burns of face and chest and oedema of eyelids. Respiratory distress was apparent immediately, with severe coughing, grey cyanosis, and much mucous discharge from nose and eyes. Was transferred to Battle Hospital and placed in oxygen and steam, with frequent local treatment to nose and eyes. Penicillin powder applied to burns. Progressive deterioration throughout the day until death at 10.33 p.m. Survived $18 \frac{1}{2}$ hours.

Case 3.-Male aged 9 days. Very slight scorching of face. Respiratory distress and cyanosis from onset. Transferred to Battle Hospital and placed in oxygen box. Much greenish-yellow mucus was aspirated from nose and pharynx. Slight deterioration throughout day. Feeds of glucosesaline given by tube were retained. At midday trachea was aspirated but no mucus obtained. Condition became steadily worse during the night. Died at $4.55 \mathrm{a} . \mathrm{m}$. on the second day. Survived 25 hours.

Case 4.-Female aged 2 days. Had seemed to be in good condition at first and during the first day. Onset of dyspnoea and cyanosis during early morning of Monday, with subsequent rapid deterioration. Died at $6.30 \mathrm{a} . \mathrm{m}$. on the second day. Survived $26 \frac{1}{2}$ hours.

Case 5.-Female aged 4 days. Some cyanotic attacks with coughing on first day, but general condition was fairly good and feeds were retained well. Slowly increasing distress on second day as the respiratory rate rose. Died at 10.45 a.m. on the second day. Survived 31 hours.

Case 6.- Female aged 8 days. Condition seemed fairly good at first, but the respiratory rate rose to 60 during the first 24 hours, after which dyspnoea increased progressively. On account of the very great respiratory distress the trachea was aspirated on the second day, on two occasions, but this produced no relief and very little mucus was obtained. Died at 6.10 p.m. on the second day. Survived 38 hours.

Case 7.-Male aged 3 days. Well, apart from slight cough during the first 12 hours. After this period similar course to Case 6. Strong baby, making violent respiratory efforts. Period of intermittent breathing preceded death at 6.30 p.m. on the second day. Survived $38 \frac{1}{2}$ hours.

Case 8.-Male aged 4 days. After some slight intermittent dyspnoea and cyanosis during the first 24 hours appeared to be improving. Much stained mucus had been aspirated from the pharynx. There was a rapid deteriora- tion with increasing dyspnoea during the evening, and he died at 9.10 p.m. on the second day. Survived 41 hours.

Case 9.-Male aged 3 days. In good condition in early stages, symptoms gradually increasing after the first 24 hours. Died at 10 p.m. on the second day. Survived 42 hours.

Case 10.-Male aged 7 days. This baby showed early signs and was one of the three (with Cases 2 and 3) who were transferred to the Battle Hospital immediately after the fire. He had improved, respiratory rate had fallen, and feeds were retained satisfactorily. Cyanotic attacks and rising respiratory rate recurred during the night of Monday and became more severe in the early morning. One unsuccessful attempt was made to suck out the trachea. A period of several hours of marked head retraction preceded death at 4 a.m. on the third day. Survived 48 hours.

Case 11.-Female aged 6 days. This baby remained in fairly good general condition until 24 hours after the fire, respiratory rate remaining in the region of 40 a minute. There was very slight scorching of the face and one hand. Pyrexia with temperature $102^{\circ} \mathrm{F}$. $\left(38.9^{\circ} \mathrm{C}\right.$.) developed during the second night, and, following this, chest symptoms and signs increased until she died at 10.24 a.m. on the third day. Survived 54 hours.

Case 12.-Male aged 2 days. Gradual development of symptoms during the first 24 hours, after which there seemed to be a steady improvement. At 2 a.m. on Tuesday became hyperpyrexial ; temperature $107^{\circ} \mathrm{F}$. $\left(41.7^{\circ} \mathrm{C}\right.$.). This subsided, but the baby did not improve further, and after repeated attacks of cyanosis and development of head retraction, died at 11 a.m. on the third day. Survived 55 hours.

Case 13.-Female aged 3 days. Course was very similar to the previous one, with pyrexia-temperature $104^{\circ} \mathrm{F}$. $\left(40^{\circ}\right.$ C.)-during the second night and final deterioration after early improvement. She died at 12.50 p.m. on the third day. Survived 57 hours.

Case 14.-Female aged 3 days: The early course was similar to previous cases, but there was some improvement in aeration during the third day and subsequently as mucus was coughed up and aspirated. Percussion drainage seemed to be increasingly effective, and on one occasion was followed by the production of a large cast. From the fifth day there was a steady improvement, though an $x$-ray film (Fig. 1) on the sixth day showed that extensive areas of collapse were present. Cortisone was reduced to $12.5 \mathrm{mg}$. eight-hourly on the fourth day, and stopped after a further 24 hours. Oxygen was gradually withdrawn and penicillin and streptomycin were stopped on the ninth day. On the eleventh day an $x$-ray film

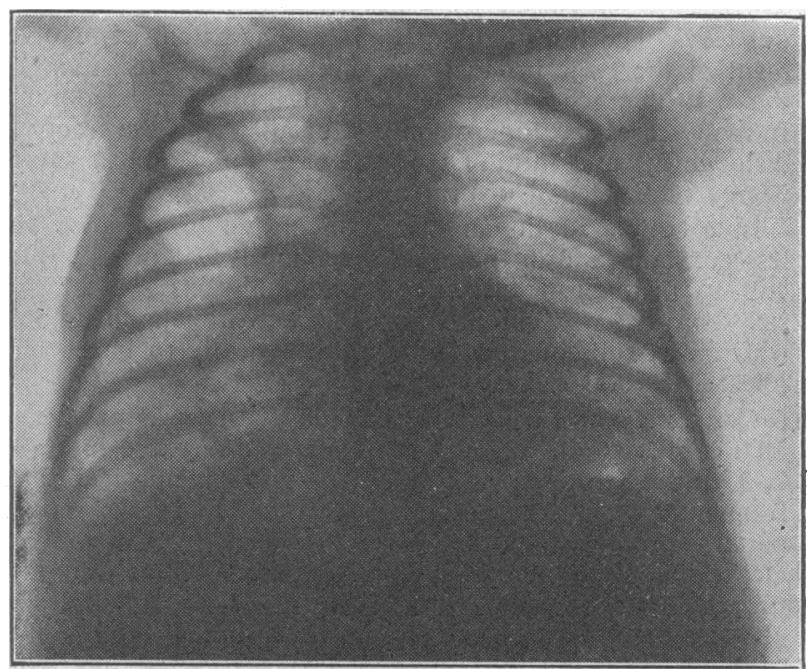

Fig. 1.-Case 14. Chest film on sixth day of illness, showing extensive areas of collapse consolidation. Later films show complete clearing. 
showed considerable clearing. There were several alarming cyanotic attacks at this late stage, but these were of brief duration. Breast-feeding was re-established, and she was discharged home fully breast-fed and symptom-free on May 5, 17 days after the fire. Subsequent $x$-ray films show clear lung fields.

Case 15.-Male aged 7 days. Course was parallel to that of Case 14, and this infant was fully breast-fed by his mother when he was discharged on May 5. Both mothers had been admitted to re-establish feeding as soon as the babies began to improve. As in Case 14, there were several brief but alarming cyanotic attacks during convalescence associated, it seemed, with the separation of bronchial casts. Some yellow staining of the skin in both these babies persisted until a few days before their discharge.

\section{Pathology}

Post-mortem examination of the respiratory tract was carried out initially by Dr. J. A. Hardy, police surgeon at Reading. Permission was given by the coroner for further investigation of the specimens to be undertaken, and accordingly one lung from each case excepting the first was made available for examination in the Department of Morbid Anatomy, Hospital for Sick Children, Great Ormond Street.

\section{Naked-eye Appearances}

The most striking changes were seen in the bronchial tree, where the formation of a membranous cast had occurred in each case. In Cases 2 and 3 this was still firmly

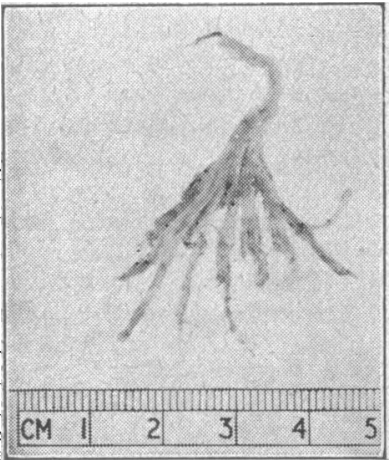

Fig. 2. - Cast of bronchial tree removed at necropsy. Black scattered throughout the specimen. flecks of carbon are seen attached to the bronchial wall, and consisted of a thick layer of greenishyellow material flecked with carbon. This replaced the normal shiny bronchial mucosa. A little yellow watery fluid was also present in the bronchial lumen. In those cases which survived longer, separation of this membrane from the bronchial wall had occurred. The cast now appeared as a firm tubular structure surrounded or indented by a quantity of sticky brownish mucoid material. Separation occurred initially in a patchy fashion so that only in those cases surviving longest was it possible to extract a whole cast of the bronchial tree without leaving portions behind (Fig. 2). The extent of involvement of the large bronchi was similar in all cases, none of the main branches being entirely devoid of a membrane. In many cases secretion of mucus together with the resultant dislodgment and infolding of the cast had led to a severe degree of bronchial obstruction.

Involvement of the smaller bronchi and bronchioles was less constant, and in the gross specimen it was usually difficult to distinguish cast formation in air passages of this size from the bronchiolitis and adjacent bronchopneumonia which was subsequently shown histologically to have complicated several cases.

Congestion and oedema of the lung tissue was present in all the specimens, but was particularly noticeable in Cases 2, 3, and 4. Interstitial emphysema and oedema were also frequently seen, with resultant accentuation of the mosaic pattern produced on the pleural surface by the lobules. Occasional large interstitial emphysematous bullae were also present. There were considerable areas of collapse and alveolar emphysema in all specimens, although the quantity of lung tissue involved in these changes varied somewhat from case to case. In most of the lungs collapse predominated over emphysema. All the specimens showed pleural haemorrhage, varying in size from scarcely perceptible petechiae up to extensive haemorrhagic areas involving a considerable proportion of the pleural surface.

\section{Histology}

Examination of the larger bronchi showed that, while the greater part of the epithelium had been destroyed, not all areas were quite so severely affected, and in a few places the epithelium had been spared completely. This was particularly noticeable where relative protection had been afforded by mucosal folds, or near the ducts of mucous glands. In the less severely affected regions the epithelial cells had desquamated either singly or in clumps. The cytoplasm was swollen, homogeneous, and intensely eosinophilic, and the nuclei either showed degenerative changes or had disappeared. In the more severely affected parts individual cellular detail was less evident. The necrotic cells had fused together, replacing the epithelium by a densely eosinophilic membrane containing occasional nuclear remnants and patchy aggregations of carbon particles.

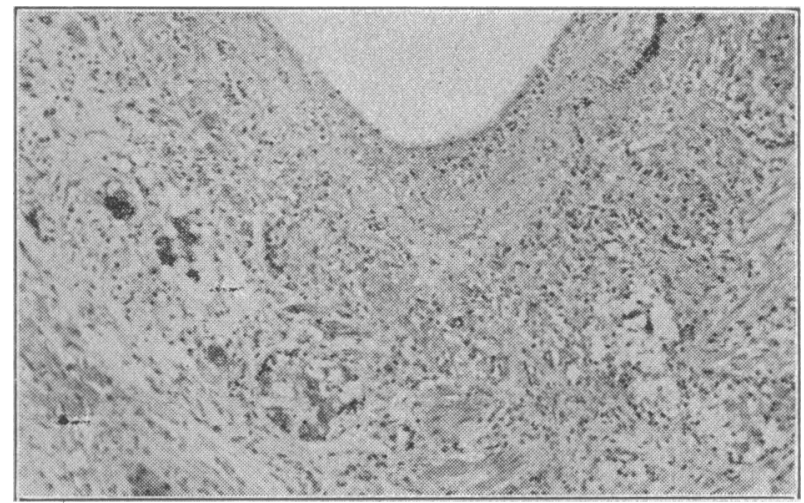

FIG. 3.-Destruction of bronchial epithelium with formation of a thick membranous cast. Cast contains carbon partic!es and is still attached to the bronchial wall. $(\times 90$. $)$

The bronchial walls were intensely congested and oedematous, and frequently haemorrhagic. Moderately numerous inflammatory cells were present in the cast and adjacent bronchial wall. These consisted of approximately equal numbers of polymorphs and mononuclear cells. At a later stage secretion of mucus from the underlying glands occurred, with resultant separation of the membrane from the bronchial wall. This process was barely starting in Cases 2 and 3 , in which most of the cast was still attached (Fig. 3), but became progressively more advanced in those cases surviving longer, when large quantities of mucus could be seen lying between the cast and the bronchial wall. In some of the bronchi this led to complete occlusion of the lumen. Where separation had occurred the bronchi were sometimes devoid of a lining epithelium, although usually a few of the basal cells had been spared. No definite evidence of epithelial regeneration was seen in any of the specimens.

Cast formation in the bronchioles was very much less extensive, the majority being uninvolved in this process. In several cases there was acute bronchiolitis, which in Cases 2,3 , and 4 had progressed to well-developed bronchopneumonia. Cases 8, 10, and 11 showed very much earlier bronchopneumonic changes. This bronchiolitis was independent of the presence of bronchiolar casts, and was commonly seen where the latter was absent. The inflammatory exudate in the bronchiolar walls was very much more cellular than that seen in relation to the casts in the large bronchi.

The alveoli were congested and oedematous, and showed well-marked collapse and emphysema. In addition to the oedema fluid the alveoli contained carbon particles, small quantities of eosinophilic fibrillary material which gave negative stains for fibrin, and moderate numbers of mono- 
nuclear cells, many of which were vacuolated. Occasional squames were present in some of the lungs, but no hyaline membrane was seen. The interstitial tissue was oedematous and often contained large air spaces (Fig. 4). There were numerous interstitial and intra-alveolar haemorrhages. The latter were not particularly extensive except in Case 5, in which large areas of the lung were involved, giving an appearance reminiscent of pulmonary infarction.

Frozen sections

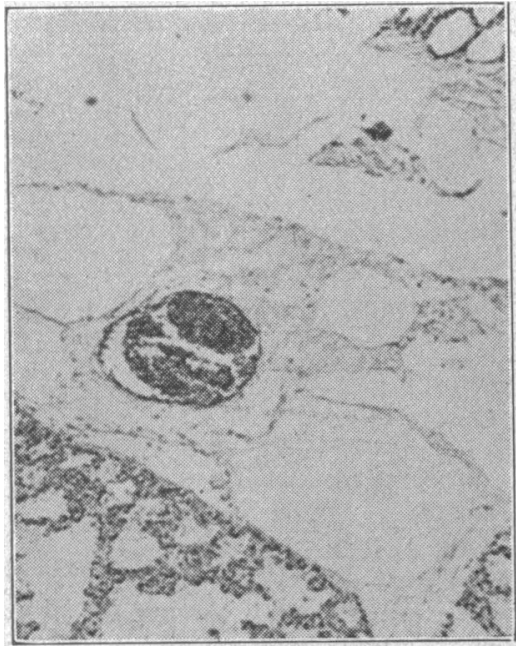

FIG. 4.-Interstitial emphysema, with large air spaces in interlobular septum. $(\times 55$.

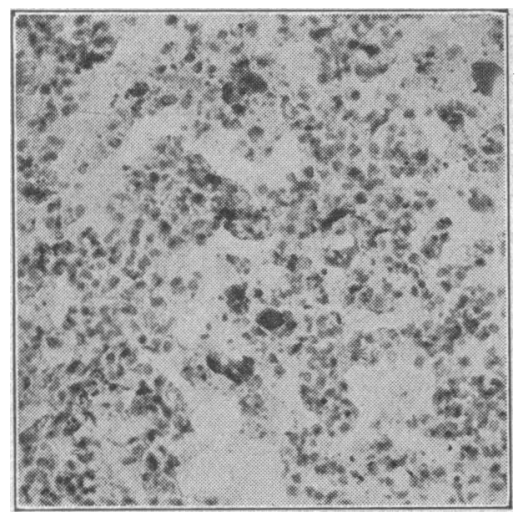

FIG. 5.-Droplets of lipoid material (ap pearing black $)$ within the alveoli. $(\times 200$.

tions of painted wood and linoleum were distilled separately. In each case a brown oily distillate was obtained. No attempt was made to analyse this, but it was smeared on slides and subjected to the same staining procedure (Scharlach $\mathbf{R}$ ) as the histological material. In the case of the distillate from the painted wood, small quantities of positively staining material were obtained, while in the case of the linoleum a considerable proportion of the distillate stained positively by this method. Thus it seemed reasonable to infer that the lipoid material in the lungs had been inhaled in the smoke.

From the gross and microscopical appearances it was not possible to determine which cases had suffered the greatest exposure to the smoke, nor was it possible to correlate the severity of the bronchial lesion with the quantity of either carbon or lipoid present.

\section{Discussion}

These 12 babies died as a result of progressive bronchial occlusion together with pulmonary oedema and infection. The first three babies to die showed less severe obstruction than the subsequent cases; little separation of the cast had occurred, but pulmonary oedema was much more pro- nounced, and there was extensive bronchopneumonia. In the later cases pulmonary oedema and infection were less prominent features, but bronchial obstruction had become much more complete as a result of secretion of mucus and displacement of the membranes cast into the centre of the bronchial lumen.

The retention of such large quantities of mucus within the bronchial tree was due largely to two factors. Firstly, much of the mucus was trapped between the bronchial wall and the cast, and removal was often further impeded by the fact that adjacent parts of the cast were still adherent to the bronchial wall. Secondly, the removal of mucus was prevented by the destruction of most of the ciliated epithelium.

The formation of the bronchial cast was attributed to irritant substances present in the smoke to which the babies were exposed. Membranous bronchitis is a recognized, though fortunately uncommon, complication of some infections, notably diphtheria, and has also been reported following the inhalation of certain war gases (Winternitz, 1920), nitrous fumes (von Oettingen, 1941), and after exposure to atomic radiation (Liebow et al., 1949). Lesions very similar to those described above were reported as occurring in some of the victims of the Coconut Grove fire.

There is every reason to believe that if the babies had survived the initial hazards of pulmonary oedema and in fection, and the later period of bronchial obstruction, complete restoration of the bronchial epithelium might have occurred, regeneration proceeding from the surviving islands of epithelium in the mucosal folds and duct orifices (Wright, 1950).

If the course of events is reviewed in the light of subsequent investigations the most important question that arises is whether anything further could have been done to help these babies. Atropine might have been given in sufficient doses to diminish secretion. It might, however, also have made secretions more viscid and less likely to separate. Humidification by mist, perhaps with the addition of a detergent, might have been used, but this could have led to fatal increase in the already great amount of fluid in the lungs. Cortisone might perhaps have been given earlier and in larger doses; but in addition to diminishing exudative responses cortisone has other effects, including that of promoting fluid retention and possibly diminishing resistance to infection. More vigorous and intensive aspiration of the lower respiratory tract might have been attempted, including perhaps aspiration through tracheotomies, but such procedures in the newborn have their own risks and probably a high mortality. They might, however, have been effective in the babies who survived to the third day, when some of the casts were beginning to separate.

The simple measures which were attempted were carried out by ourselves and by the nursing staff. The latter, working in eight-hour shifts, showed skill and gentleness that were all that could be desired. Percussion drainage was at first performed by one of us, but later, too, this was taken on by the nursing staff in some cases.

A tragic event such as this should not perhaps be used as an argument for or against any system of care. The custom of putting all the babies into a nursery for the night so that the mothers can sleep undisturbed is a widespread one, and is particularly the rule in smaller maternity homes. Quite apart from the possibility of a disaster such as this, the system is, we think, a bad one, and we would repeat the opinion frequently given by paediatricians and obstetricians that the proper place for the normal newborn baby is in a cot close to the mother's bed.

\section{Summary}

An account is given of the Dellwood fire which caused the death of 13 newborn babies. Two babies survived and are now apparently normal. One baby was found dead. The others died within three days of the fire. 
The symptoms were those of increasing respiratory distress, pyrexia, cough, and cyanotic attacks. Death was due to bronchopneumonia in the first 24 hours, or later to bronchial obstruction caused by casts consisting mainly of fused necrotic epithelial cells. The bronchial changes were due to inhalation of smoke.

Treatment included oxygen, chemotherapy, cortisone, percussion and postural drainage, and aspiration of mucus from the mouth and nasopharynx. Tracheal aspiration and gastric oxygen were used, but the results were disappointing. The question of possible alternative treatment is discussed.

Among the many who helped us during these babies' illness we would like especially to record our thanks to Dr. B. Schlesinger, Dr. D. Foskett, and Mr. E. Hunt Williams. Acknowledgments are due to Dr. J. A. Hardy, the police surgeon in Reading, who on H.M. Coroner's instructions carried out the post-mortem examinations. In later investigations valuable technical advice was received from Mr. L. C. Nickolls, Director of the Metropolitan Police Laboratory. Valuable help was received in the laboratory investigations from Dr. C. de Courcy and Mrs. A. Hopkins. We are also grateful to Dr. M. Bodian for assistance in the preparation of this paper, and to Mr. Derek Martin, of the Department of Medical Illustration, Great Ormond Street, for the photographs.

REFERENCES

Liebow, A. A., Warren, S., and De Coursey, E. (1949). Amer. J. Path. 25, 853.

von Oettingen, W. F. (1941). Publ. Hlth Bull. (Wash.), No. 272. Winternitz, M. C. (1920). Pathology of War Gas Poisoning. Yale Univ. Press, New Haven.

Wright, G. P. (1950). An Introduction to Pathology. Longmans, Green, London

\section{THE SOCIAL AND PSYCHOLOGICAL BACKGROUNDS OF TUBERCULOUS CHILDREN}

\author{
BY \\ DINA ROSENBLUTH, B.A. \\ AND \\ JOHN BOWLBY, M.A., M.D. \\ Deputy Director, Tavistock Clinic
}

One of the projects undertaken by a research team investigating the effects on personality development of separation from the mother in early childhood was a follow-up of children who, because they had tuberculosis, had been separated from their mothers, and in a sanatorium, for a period during their first years of life (Bowlby, Ainsworth, Boston, and Rosenbluth, 1955). This required us to investigate the social background of these children, and the present study is a by-product of the main research. It gives some findings relating to the economic and housing conditions, the extent of family illness and disruption, and some of the psychological attitudes found among members of these families during the year 1950. Although we are aware that what is described will not be new to workers in the field of tuberculosis, our impression is that that knowledge exists in rather a fragmentary form.

The gross sample studied was obtained by extracting from the records of a sanatorium the record of every child admitted between birth and 4 years, between January 1, 1940, and November 30, 1948, inclusive. From this sample were eliminated children whose primary tuberculosis was complicated by bone or abdominal infection, those who had left the county of Middle- sex, who had gone into the care of other institutions, or who had died, and those who were not yet of school age. The resulting sample consisted of 60 children-41 boys and 19 girls. They had all returned to their homes and were attending schools in the county. The present addresses of the children were traced with the help of the chest clinic and education authority records.

The need to make direct systematic inquiry of the families in which we were interested was recognized by the staffs of chest clinics, and in arranging the interviews it was of great help to be able to state that both the sanatorium and the local chest clinics were co-operating in the research. The warm welcome and readiness to talk which the psychiatric social worker met with in most families are believed to be a tribute to the sanatorium, which most families remembered with gratitude. Lack of co-operation was on each occasion related to reluctance to disclose an especially difficult or disturbed family situation.

The total sample of 60 children came from 57 families. Two families, containing three children, refused altogether to co-operate, and one of two siblings was in a residential school. The total number of families remaining is therefore 55 , containing 56 children.

The average length of interviewing time was four to five hours, usually spread over two or three visits. The psychiatric social worker spent a little time at the beginning of the first interview explaining the purpose of the research. Once the family had agreed to cooperate she attempted to guide the interview so as to cover the main points on which information was sought. Where there was reluctance to give information this was not pressed for. On the other hand, the parents often talked at length about their problems, and in many cases revealed their attitudes to tuberculosis and to the tuberculosis service. It was thus, incidentally and unasked for, that much of our material was obtained.

\section{Economic and Housing Conditions}

The families were rated for economic and for housing conditions, each on a four-point scale. The rating "A" for economic conditions implies an income on which the family could manage fairly well and afford an annual holiday. The rating " $B$ " implies an economic situation that is fairly adequate. The rating " $\mathrm{C}$ " implies a rather poor income, usually only one parent being at work, in an unskilled occupation, and the family finding it difficult to make ends meet; a summer holiday was out of the question, or possible only once in a while and at great sacrifice. The rating " $D$ " implies that the families suffered real economic hardship. These were the families the mothers of which were widows and had to live on widows' pensions supplemented by a little earning of their own or by the National Assistance Board. The distribution of ratings is shown in Table 1.

TABle I.-Economic Circumstances of 55 Families

\begin{tabular}{llllllc} 
Rating & & & & & \multicolumn{2}{c}{$\begin{array}{c}\text { No. of } \\
\text { Families }\end{array}$} \\
A: Comfortable & $\ldots$ & $\ldots$ & $\ldots$ & $\ldots$ & $\ldots$ & $\mathbf{6}$ \\
B: Fairly adequate & $\ldots$ & $\ldots$ & $\ldots$ & $\ldots$ & $\ldots$ & 20 \\
C: Poor & $\ldots$ & $\ldots$ & $\ldots$ & $\ldots$ & $\ldots$ & 16 \\
D: Economic hardship & $\ldots$ & $\ldots$ & $\ldots$ & $\ldots$ & 13
\end{tabular}

Not infrequently the psychiatric social worker heard accounts of severe economic hardship in the parent's own childhood, and also during the pre-war or early war years, when the sample child was an infant. But with the great majority of the families the economic situation had taken a marked turn for the better in the post-war years. At the time of the inquiry the black spot was the 13 families rated " $D$ " 